\title{
DETERMINAÇÃO DA CONDUTIVIDADE HIDRÁULICA DAS PRINCIPAIS UNIDADES GEOLÓGICO-GEOTÉCNICAS DE SANTA MARIA - RS
}

\section{DETERMINATION OF THE HYDRAULIC CONDUCTIVITY OF THE MAIN GEOLOGICAL- GEOTECHNICAL UNITS OF SANTA MARIA - RS}

\section{Rinaldo J. B. PINHEIRO', Andréa Valli NUMMER ${ }^{2}$, Ana Carla RAUBER ${ }^{3}$}

(1) Pós-Graduação em Engenharia Civil, Centro de Tecnologia, Universidade Federal de Santa Maria/ Cidade Universitária, Av. Roraima, 1000, CEP 97100-900, Santa Maria, RS. Endereço eletrônico: rinaldo@ufsm.br (2) Pós-Graduação em Geografia, Centro de Ciências Naturais e Exatas, Universidade Federal de Santa Maria/ Cidade Universitária, Av. Roraima, 1000, CEP 97100-900, Santa Maria, RS. Endereço eletrônico: a.nummer@ gmail.com

(3) Pós-Graduação em Engenharia Civil, Centro de Tecnologia, Universidade Federal de Santa Maria/ Cidade Universitária, Av. Roraima, 1000, CEP 97100-900, Santa Maria, RS. Endereço eletrônico: acrauber@yahoo.com.br

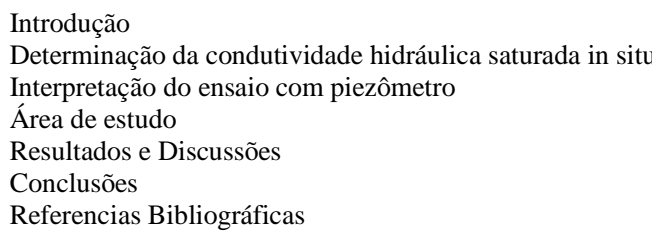

\begin{abstract}
RESUMO - Determinou-se a condutividade hidráulica saturada das Unidades Geotécnicas sedimentares de Santa Maria-RS utilizando a técnica de piezômetro escavado de Casagrande. O uso desta técnica procurou resolver problemas de alteração da estrutura, amolgamento, fuga lateral da água e a variabilidade de resultados obtidos de outros métodos. As Unidades Geotécnicas mostraram diferentes valores de condutividade hidráulica que ocorre principalmente pela variação granulométrica, cimentação e estruturas sedimentares destes materiais. Valores baixos de condutividade hidráulica foram obtidos para a Formação Santa Maria (exceto Arenito Basal) e mais elevados para Depósitos Coluvionares e Fluviais. Os resultados foram satisfatórios em relação ao tempo de ensaio e valores obtidos, confirmando e quantificando as informações contidas no na Carta Geotécnica de Santa Maria.

Palavras-chave: Condutividade Hidráulica, Permeabilidade, Piezômetros Escavados.
\end{abstract}

\begin{abstract}
Hydraulic conductivity tests were conducted in sedimentary Units Geotechnical Santa Maria-RS using the piezometer in a borehole from Casagrande. The use of this technique solved the problems of structure change, remolded, side-wall leakage of the water and the variability in results obtained by other methods. The Geotechnical Units showed different hydraulic conductivity values which mainly occurs by grain size variation, cementing and sedimentary structures of these materials. Low values of hydraulic conductivity were obtained for Formation Santa Maria (except basal sandstone) and higher for Colluvial and Fluviais Deposits. Os results were satisfactory in relation to the test of time and values confirming and quantifying the information contained in Geotechnical Map of Santa Maria.
\end{abstract}

Keywords: Hydraulic Conductivity, Permeability, Piezometers in a Borehole.

\section{INTRODUÇÃOO}

A investigação do subsolo, incluindo a determinação das propriedades dos solos, é uma etapa essencial nas análises e projetos geotécnicos. A determinação das propriedades mecânicas e hidráulicas dos solos através de ensaios de laboratório e de campo permite uma análise mais precisa do comportamento destes materiais. Ensaios hidráulicos como os de condutividade podem ser realizados em campo e em laboratório.

Ensaios realizados em laboratório como o de condutividade hidráulica saturada podem apresentar problemas de interpretação decorrentes da heterogeneidade das amostras e do efeito do amolgamento resultante do processo de amostragem em campo (amostras indeformadas), portanto são geralmente utilizados para o estudo em solos compactados.
Além disto, os ensaios de laboratório requerem maior tempo de execução. Já os ensaios de condutividade hidráulica de campo são geralmente realizados para determinação deste parâmetro em solos naturais, pois reduzem os problemas de amolgamento e abrangem volume maior de solo, minimizando efeitos de escala. Em contrapartida a interpretação dos resultados destes ensaios é geralmente baseada em modelos empíricos ou semi-empíricos, dadas as complexas condições de contorno que se estabelecem durante a infiltração de água no solo.

A condutividade hidráulica saturada é uma das propriedades de maior relevância para estudos de movimento de água, substâncias químicas e solutos no solo. Este coeficiente representa uma das propriedades do solo de 
mais alta variabilidade e, segundo autores como Lumb (1966), Uzielli (2008) e Nagy et al. (2013), a variação pode ser tão elevada como $240 \%$. Sua determinação depende de vários atributos do solo, principalmente da densidade (peso específico natural), densidade das partículas (peso específico real dos grãos), porosidade total, macro e microporosidade (Mesquita \& Moraes, 2004). Além destas, a escolha do tipo de método de ensaio também pode influenciar os valores dos resultados obtidos. Segundo Reichardt (1996) dentre as variáveis que influenciam o fluxo de água, a condutividade hidráulica se destaca, sendo um parâmetro que representa a facilidade com que o solo/rocha transmite água. Desta forma, o valor máximo de condutividade hidráulica é atingido quanto o solo/rocha sedimentar se encontra saturado, e é definido como condutividade hidráulica saturada. A partir da condutividade hidráulica saturada e utilizando modelos matemáticos pode-se determinar a condutividade hidráulica não saturada.

A condutividade hidráulica é o coeficiente de proporcionalidade da lei de Henry Darcy de 1856, o qual pode ser escrito conforme apresentado na equação 1 .

$$
q=k . i . A=k \cdot \frac{\Delta H}{L} \cdot A
$$

$\mathrm{q}=$ taxa de fluxo $\left(\mathrm{m}^{3} / \mathrm{s}\right)$

$\mathrm{k}=$ condutividade hidráulica $(\mathrm{m} / \mathrm{s})$

$\mathrm{i}=$ gradiente hidráulico (adimensional $=$ $\Delta \mathrm{H} / \mathrm{L})$

$\Delta \mathrm{H}=$ perda de carga $(\mathrm{m})$ através da amostra de comprimento $\mathrm{L}(\mathrm{m})$

$\mathrm{A}=$ área da seção transversal perpendicular ao fluxo $\left(\mathrm{m}^{2}\right)$

A condutividade hidráulica da lei de Darcy depende não somente das propriedades do meio poroso, mas também das propriedades do líquido permeante. Daniel (1994) exemplifica o caso de areias, que podem ter baixa condutividade hidráulica se permeadas com óleo de motor quando comparadas com a água (devido ao óleo ser mais viscoso que água). Uma forma alternativa para escrever a lei de Darcy está mostrada na equação 2 .

$$
q=K \cdot \frac{\gamma}{\mu} \cdot \frac{\Delta H}{L} \cdot A
$$

$\mathrm{K}=$ permeabilidade intrínseca do solo $(\mathrm{m} / \mathrm{s})$ $\boldsymbol{\gamma}=$ peso específico do liquido permeante $\left(\mathrm{g} / \mathrm{m}^{2} / \mathrm{s}^{2}\right)$

$\mu=$ viscosidade do liquido permeante $(\mathrm{g} / \mathrm{m} / \mathrm{s})$

Segundo Olson \& Daniel (1981) e Reichardt (1996) a permeabilidade intrínseca é função somente das propriedades do material poroso (arranjo das partículas e umidade), não do liquido permeante. Engenheiros Civis e especialistas em água subterrânea tradicionalmente usam o termo condutividade hidráulica ao invés de permeabilidade intrínseca, pois a densidade e a viscosidade da água são relativamente constantes (a condutividade hidráulica altera-se cerca de 3\% para mudanças de $1^{\circ} \mathrm{C}$ na temperatura, mas este efeito é menor para intervalos normais de temperatura).

Os Engenheiros Civis tradicionalmente chamam o coeficiente $\mathrm{k}$ da equação1 de coeficiente de permeabilidade, apesar da confusão que pode causar com o conceito de permeabilidade intrínseca, pois justificam que Henri Darcy chamou o parâmetro de un coefficient dépendant de la pérmeabilité (um coeficiente que depende da permeabilidade) e que $\mathrm{o}$ autor não mencionou o termo condutividade hidráulica (Daniel, 1994). Já cientistas de solo e hidrogeologistas têm tradicionalmente chamado este coeficiente de condutividade hidráulica, pois numerosos outros fenômenos físicos são descritos por uma equação de forma idêntica a da lei de Darcy, e o coeficiente de proporcionalidade nestas equações de condução são usualmente denominados de condutividade (por exemplo, condutividade térmica) do meio condutor. Daniel (1994) recomenda, portanto que denomine-se o coeficiente $\mathrm{k}$ da equação 1 da lei de Darcy de condutividade hidráulica a fim de ser compatível com os outros campos da ciência. Como é comum utilizar o termo permeabilidade para o coeficiente da equação 1 , o que pode criar uma confusão com a permeabilidade intrínseca (coeficiente $\mathrm{K}$ da equação 2), ao se utilizar o termo condutividade hidráulica elimina-se qualquer confusão com a permeabilidade intrínseca.

Tendo em vista as diferenças conceituais e de uso do termo permeabilidade, bem como dos métodos utilizados para obtenção desta propriedade hidráulica, este artigo tem como objetivo apresentar a metodologia de obtenção 
e determinação da condutividade hidráulica saturada (ksat) com a utilização do piezômetro de Casagrande e sua aplicação nas rochas sedimentares e depósitos superficiais que compõem as Unidades Geotécnicas de Santa Maria definidos por Maciel Filho (1990), avaliando a eficácia do método empregado.

Segundo Chapuis (1989), o aumento de problemas relacionados com contaminação do lençol freático têm reativado pesquisas em ensaios de campo para determinação da condutividade hidráulica. A base teórica destes ensaios é bem desenvolvida. Entretanto, detalhes de execução em campo têm efeitos significativos nos resultados dos ensaios o que talvez, seja a principal razão pela qual os ensaios de condutividade hidráulica de campo ainda não estejam formalmente normalizados.

\section{DETERMINAÇÃO DA CONDUTIVIDADE HIDRAULICA SATURADA IN SITU}

Os ensaios de campo têm como objetivo determinar a condutividade hidráulica das rochas e depósitos naturais. Estes ensaios têm como grande vantagem envolverem uma massa de solo muito maior e, portanto, levam em consideração a heterogeneidade e anisotropia dos materiais.

Fiori et al. (2010), apresentaram um estudo mostrando a variabilidade da condutividade hidráulica das principias classes de solos do estado de Goiás, avaliando seus horizontes superficiais. Utilizaram no estudo o método dos anéis concêntricos e open and hole, similar ao ensaio de furo de sondagem (ABGE, 2013).

Para autores como Olson \& Daniel (1981) e Tavenas et al. (1983), medidas diretas da condutividade hidráulica em furos de sondagem não são precisas e não são recomendadas, principalmente para materiais argilosos $(\mathrm{k}<10$ ${ }^{7} \mathrm{~m} / \mathrm{s}$ ).

O método dos anéis concêntricos, na realidade, não determina a condutividade hidráulica mas sim a capacidade de infiltração (fluxo não saturado), pois se desconhece a priori o gradiente hidráulico. Já o ensaio em furo de sondagem, apesar de sua simplicidade e baixo custo, apresenta uma alta dispersão e problemas associados com o fluxo de água pela parede entre o furo e o tubo de PVC utilizado como revestimento.

Daniel (1989) forneceu uma análise excelente de nove métodos para estimar a condutividade hidráulica de campo de camadas de argila compactada. Destacam-se os métodos com o permêametro de Boutwell, onde num furo aberto é instalado uma camisa (tubo) e selado com argamassa no espaço entre o tubo o furo de sondagem. Este tubo é preenchido com água e realizado o ensaio com carga decrescente. Após a determinação da condutividade hidráulica, o furo é aprofundado por sondagem, o permeâmetro é remontado e o ensaio é realizado novamente.

Outros dois métodos são o permeâmetro de furo de carga constante e as sondas porosas. No primeiro uma carga constante é mantida pelo fornecimento de água e a vazão é medida através de um furo de sondagem com vedação na superfície. No segundo, sondas porosas são cravadas ou empurradas para dentro do solo, e os ensaios podem ser de carga constante ou variável, tendo duas variantes, ensaio com base permeável ou ensaio com base impermeável. Em solos naturais a cravação pode afetar a estrutura do solo e influenciar nos valores medidos de condutividade.

Para tentar resolver os problemas de alteração da estrutura, amolgamento, ou fuga lateral da água entre o contato dos tubos, sondas e a variabilidade de ensaios em furos simples de sondagem é que se propõe a utilização da técnica de piezômetros (tipo Casagrande) para determinação da condutividade hidráulica saturada em solos naturais e compactados.

Os piezômetros são instrumentos amplamente utilizados na prática de engenharia geotécnica. A determinação do coeficiente de condutividade hidráulica, por meio desse instrumento, apresenta como principal vantagem $o$ fato do ensaio ser de fácil montagem e rápida execução.

Os piezômetros podem ser escavados ou cravados. A utilização de piezômetros cravados é desaconselhada, já que pode ocorrer amolgamento do solo em volta da ponteira de cravação (Tavenas et al., 1986). Os piezômetros escavados são executados abrindo-se primeiramente um furo de sondagem com diâmetro de 6 a $20 \mathrm{~cm}$. No interior do furo de sondagem é montado um piezômetro, similar aos utilizados para o monitoramento de poro-pressão. A 
diferença básica é que o tubo central do piezômetro é conectada uma bureta (carga variável) ou um pequeno reservatório (carga constante) a partir da qual se mede o volume de água infiltrado durante $\mathrm{o}$ ensaio num determinado intervalo de tempo.

Neste estudo os ensaios com a técnica do piezômetro foram realizados em furos de sondagem executados com trado manual ou mecânico, a profundidade variável e diâmetro de aproximadamente $6,5 \mathrm{~cm}$ a $8,5 \mathrm{~cm}$ (D). A execução do ensaio se deu conforme os passos descritos a seguir. No furo foi instalado uma tubulação de PVC de $3 \mathrm{~cm}$ de diâmetro e comprimento variável em função da profundidade desejada para o ensaio (para profundidades maiores utiliza-se os furos executados pelas sondagens tipo SPT). A parte final do tubo de PVC (ponteira filtrante) têm comprimento variável (L) de $15 \mathrm{~cm}$ até $1 \mathrm{~m}$ apresentando ranhuras de $2 \mathrm{em} 2 \mathrm{~cm}$ que são pequenos cortes para percolação de água. $\mathrm{O}$ espaço entre a parede do furo e a ponteira filtrante foi preenchido com material granular (filtro), constituído de uma areia grossa selecionada. Acima do trecho corresponde ao filtro executou-se uma camada selante (bentonita mais água) e, acima desta, quando necessário preencheu-se o restante do furo com solo local (Figuras 1 a 3 ).

O ensaio de condutividade hidráulica com o piezômetro escavado tem início quando a expansão da bentonita for completada, garantindo o selamento perfeito. Basicamente, o procedimento do ensaio consiste na medição do tempo necessário, para que infiltre no solo um volume conhecido de água, mantendo-se a carga hidráulica constante no interior do furo (ensaio de carga constante) ou, alternativamente, a medição do tempo necessário para a carga hidráulica cair de um nível $\mathrm{H}_{1}$ para um nível $\mathrm{H}_{2}$ (ensaio de carga variável).

Nos ensaios de carga constante, a carga hidráulica é mantida sem variação $\left(\mathrm{H}_{\mathrm{c}}\right)$, com a colocação de água através de recipientes de volume conhecido ou utilizando hidrômetros para vazões muito elevadas. Nos ensaios de carga variável uma bureta graduada (diâmetro de $1,5 \mathrm{~cm}$ ) é conectada a um tubo acima da superfície do solo, auxiliando na leitura do volume de água infiltrada no solo. Pode-se observar nas figuras 1,2 e 3 a execução dos ensaios de campo (montagem e instalação do piezômetro).

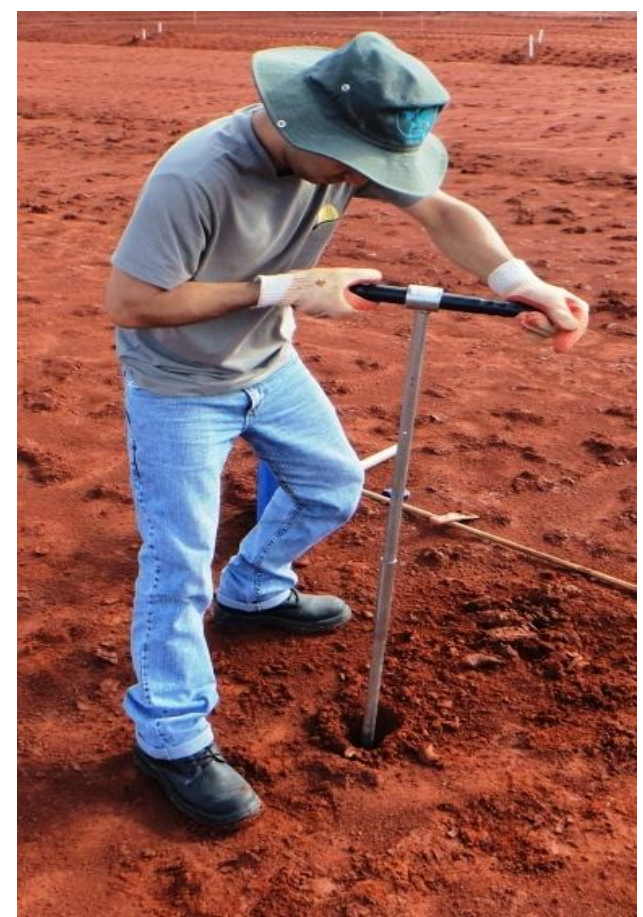

(a)

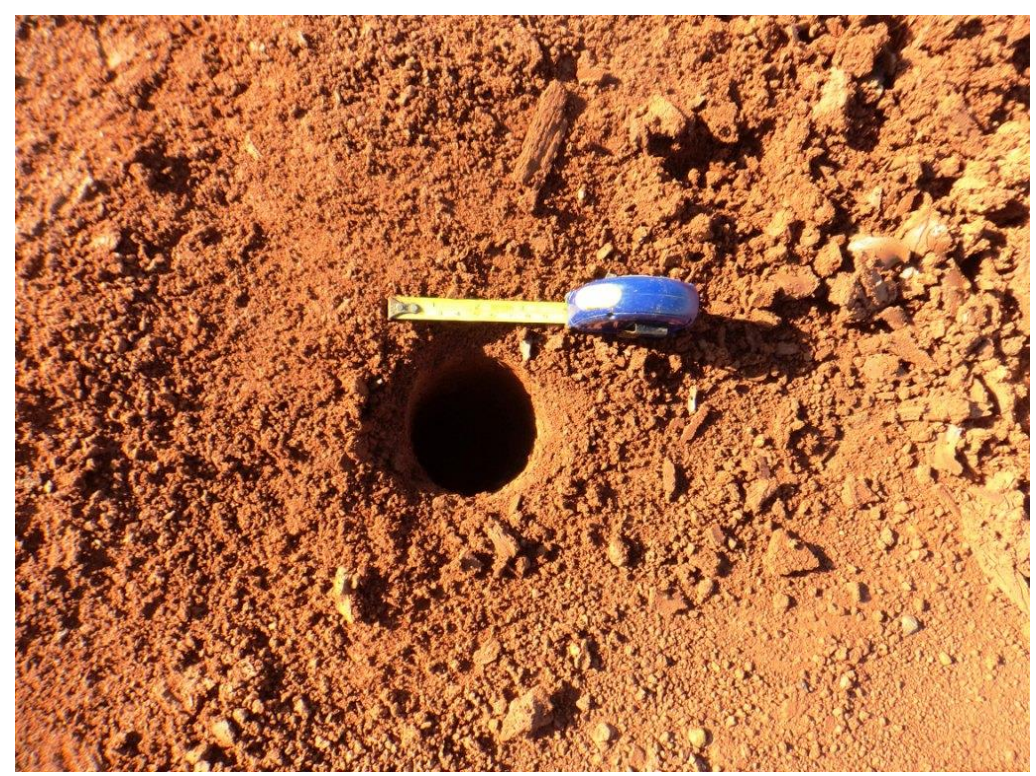

(b)

Figura 1 - (a) Execução do furo a trado manual para profundidades pequenas; (b) furo concluído pronto para montagem do piezômetro. 


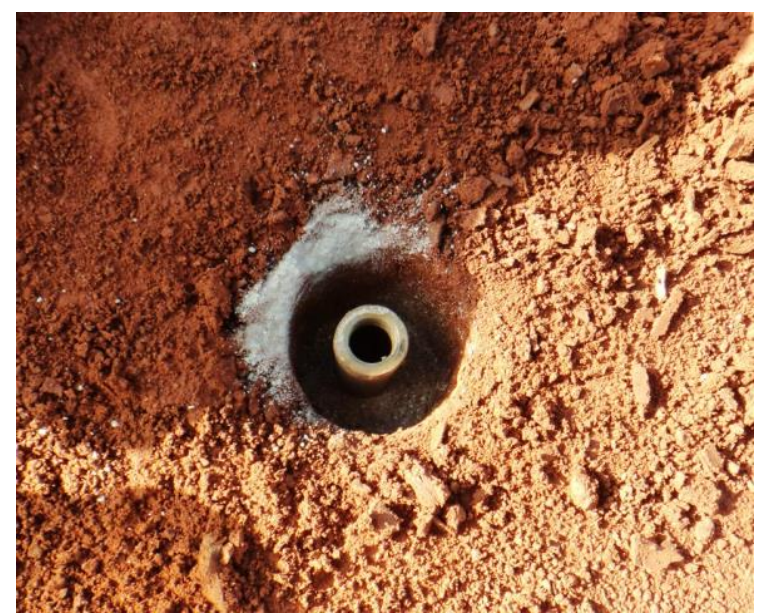

(a)

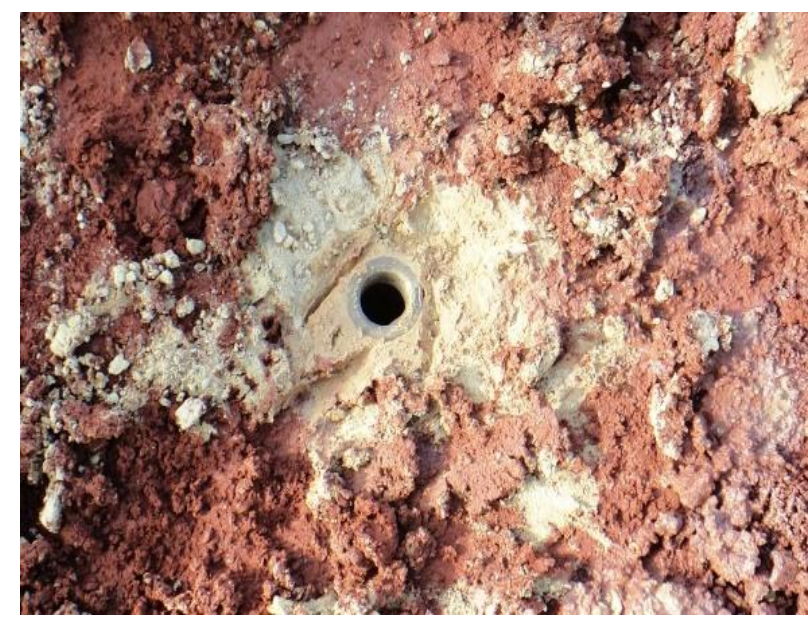

(b)

Figura 2 - (a) Furo com tubo de PVC e filtro de areia; (b) furo pronto com selamento de bentonita.

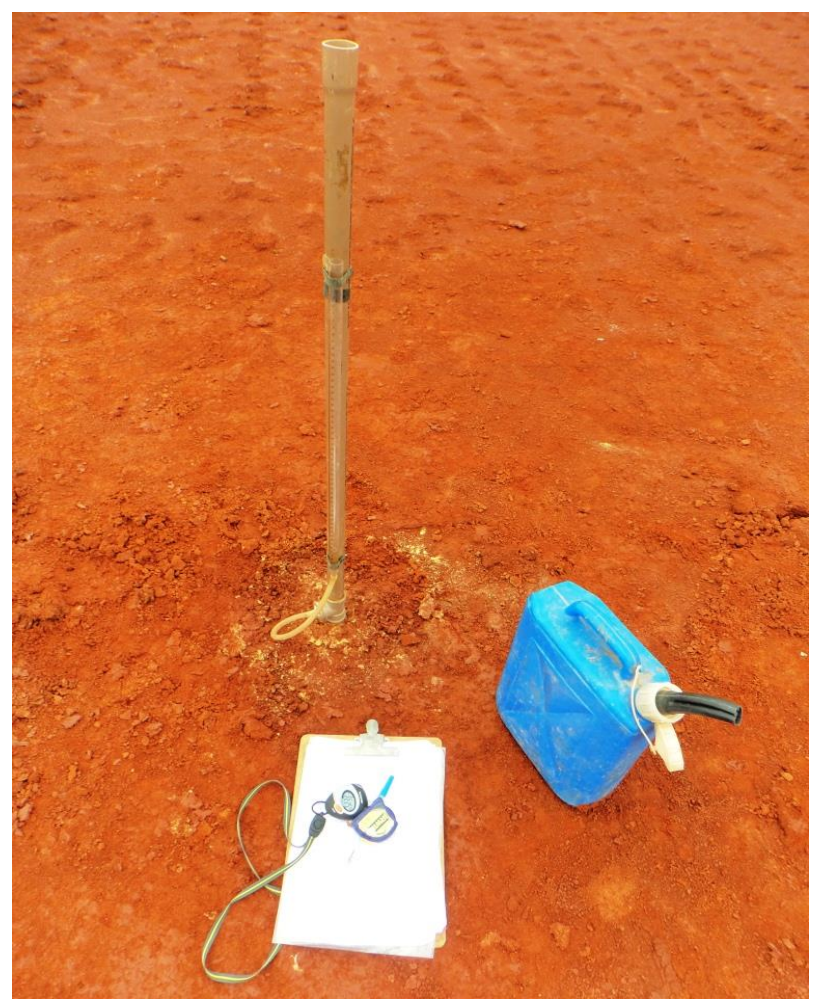

(a)

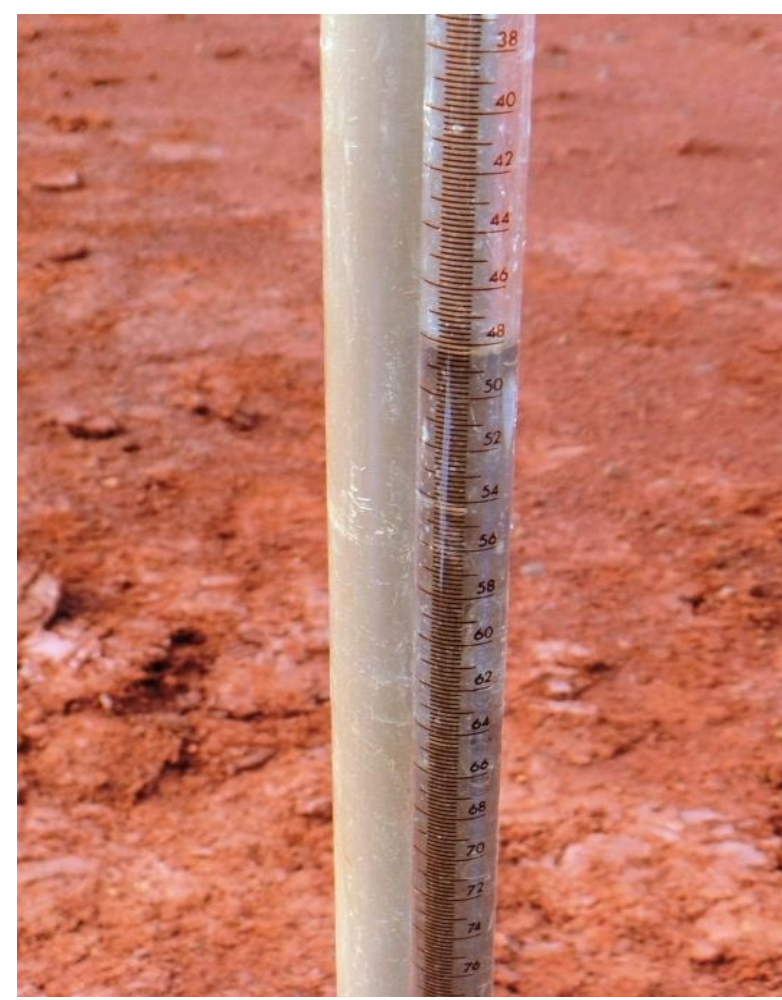

(b)

Figura 3 - (a) Sistema de medição instalado para ensaio de carga variável; (b) detalhe da bureta para leitura das variação de carga hidráulica.

Conforme Tavenas et al. (1986), o ensaio de carga variável tem sido utilizado no caso de solos com condutividade hidráulica muito baixa, como argilas moles. Esta situação está sendo modificada nos últimos anos, devido à disponibilidade de equipamentos para ensaio de carga constante com base no princípio do vaso de Mariotte, os quais tornam este tipo de ensaio mais rápido de serem executados em solos argilosos. Segundo Herzog (1994), o ensaio de carga variável é utilizado em solos granulares, devido principalmente à simplicidade e rapidez de execução.

\section{INTERPRETAÇÃO DO ENSAIO COM PIEZÔMETRO}

A equação básica para a determinação do coeficiente de condutividade hidráulica a partir dos resultados de ensaios com piezômetros foi apresentada por Hvorslev (1951). Esta equação requer o conhecimento da relação entre a carga hidráulica aplicada 
no interior do furo e a vazão medida durante o ensaio, além do fator de forma da ponteira (F). Esse fator de forma $F$ (equação 5) é uma função da geometria do piezômetro e do tipo de ensaio (com aplicação de carga hidráulica constante ou variável), que representa a solução analítica fechada da equação de Laplace para um elipsóide equivalente contido na região cilíndrica do filtro granular (cylindrical injection zone). A utilização desta equação também pressupõe que o solo seja homogêneo e isotrópico. A Figura 4 apresenta um esquema com os parâmetros geométricos necessários para o cálculo da condutividade hidráulica em ensaios com carga hidráulica constante e variável.

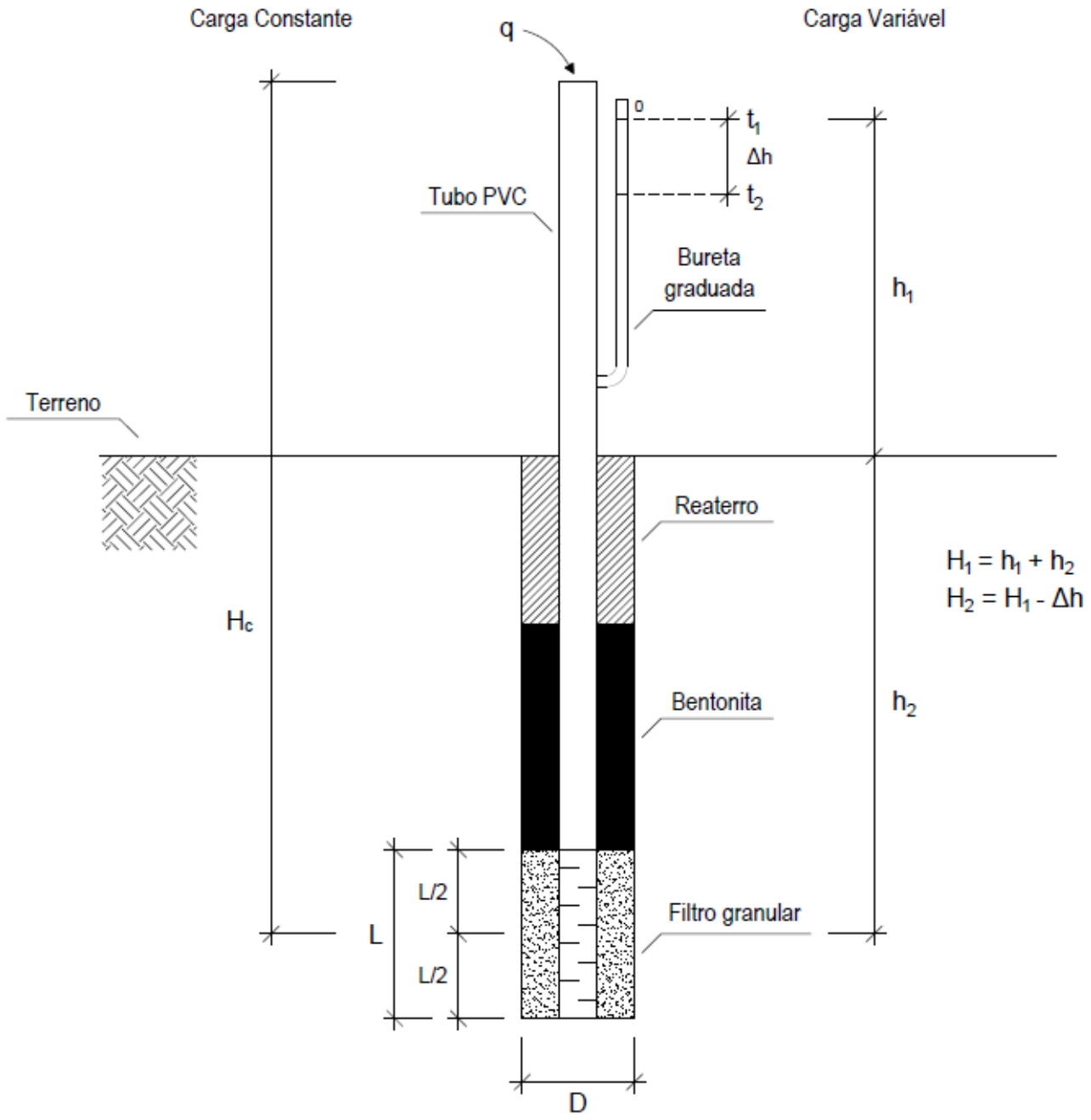

Figura 4. Esquema representativo para entendimento e cálculo da condutividade hidráulica com a técnica do piezômetro escavado.

Para uma vazão q (vazão estabilizada) no piezômetro, sob uma carga hidráulica constante $\mathrm{H}_{\mathrm{c}}$, propõe-se a utilização da equação 3 e para o ensaio realizado com carga hidráulica variável, utiliza-se a equação 4 (Hvorslev, 1951)

$$
\begin{aligned}
& k=\frac{q}{F \cdot H c} \\
& k=\frac{A}{F} \cdot \frac{\ln \left(H_{1} / H_{2}\right)}{t_{2}-t_{1}}
\end{aligned}
$$

$$
F=\frac{2 \cdot \pi \cdot L}{\ln \left[\frac{m \cdot L}{D}+\sqrt{\left.1+\left(\frac{m \cdot L}{D}\right)^{2}\right]}\right.}(5)
$$

onde:

$\mathrm{k}=$ condutividade hidráulica $(\mathrm{m} / \mathrm{s})$

$\mathrm{q}=$ vazão estabilizada $\left(\mathrm{m}^{3} / \mathrm{s}\right)$

$\mathrm{Hc}=$ carga hidráulica constante $(\mathrm{m})$

$\mathrm{H}_{1}$ e $\mathrm{H}_{2}$ as cargas hidráulicas obtidas nos tempos $t_{1}$ e $t_{2}$ respectivamente

$\mathrm{d}=$ diâmetro do tubo $(\mathrm{m})$ 


$$
\begin{aligned}
& D=\text { diâmetro do filtro }(\mathrm{m}) \\
& \mathrm{L}=\text { altura do filtro }(\mathrm{m}) \\
& \mathrm{A}=\text { seção transversal do filtro }\left(\mathrm{m}^{2}\right) \\
& \mathrm{F}=\text { fator de forma }
\end{aligned}
$$

$\mathrm{O}$ fator de forma $\mathrm{F}$ tem sido objeto de consideráveis discussões na literatura geotécnica, sendo que autores como Hvorslev (1951), Wilkinson (1968), Brandt \& Premchitt (1980) e outros propuseram formulações para a sua obtenção. A equação 5 introduz um parâmetro "m" que quantifica as diferenças entre as diversas modificações propostas para o fator $\mathrm{F}$ (variando entre 1,0 e 1,5). A figura 5 mostra as curvas resultantes da tentativa de normalização do fator $\mathrm{F}$ pelo diâmetro do furo de sondagem (D) considerando a geometria do ensaio apresentadas por Tavenas et al. (1990) para comparar as diversas soluções teóricas na literatura para o ensaio de carga variável.

A utilização destas soluções implica na previsão de $\mathrm{F} / \mathrm{D}$ (e, consequentemente, de k) com diferenças de até $40 \%$. De forma análoga ao ensaio de carga constante, os valores de F/D previstos pela solução de Hvorslev (1951) situam-se no limite inferior do intervalo de variação das diferentes soluções. Herzog (1994) comparou algumas soluções teóricas para a interpretação do ensaio de carga variável, concluindo que a escolha da solução teórica influencia o valor calculado de $\mathrm{k}$ de forma mais intensa no caso de solos granulares. Nas análises numéricas realizadas por Tavenas et al (1986), os valores derivados da relação F/D praticamente coincidiram com os previsto pela solução teórica de Randolph \& Booker (1982), indicada na figura 5. Portanto ao adotar-se uma relação entre comprimento e diâmetro do filtro igual a $\mathrm{L} / \mathrm{D}=5$, estas diferença são mais reduzidas independente da solução teórica adotada, e adotando o parâmetro $\mathrm{m}=1$, correspondente à formulação sugerida por Hvorslev (1951).

Segundo De Groot \& Lutenegger (1994), vários autores recomendam adotar a relação $\mathrm{L} / \mathrm{D}=5$ pois representam adequadamente, os efeitos de escala no valor medido da condutividade hidráulica. Deve-se portanto selecionar com cuidado a solução teórica para interpretação dos resultados dos ensaios de ponta aberta. Isto é válido para os ensaios com piezômetros, onde as mesmas soluções são aplicáveis. Chapuis (1989) realizou uma avaliação dos vários fatores de forma propostos por métodos analíticos (Hvorslev, 1951), métodos numéricos (Randolph \& Brooker, 1982; Tavenas et al., 1986) e o método da analogia elétrica para os ensaios de condutividade hidráulica em furos de sondagem e piezômetros e concluiu que a equação 5 (elipsóide) fornecem bons resultados quanto a relação $1<\mathrm{L} / \mathrm{D}<10 \mathrm{e}$ resultados não satisfatórios para $\mathrm{L} / \mathrm{D}<1$.

Substituindo o fator de Forma (equação 5) nas equações 3 e 4, resultam as equações 6 e 7 para determinação da condutividade hidráulica em ensaios com piezômetros escavados com carga constante e variável respectivamente.

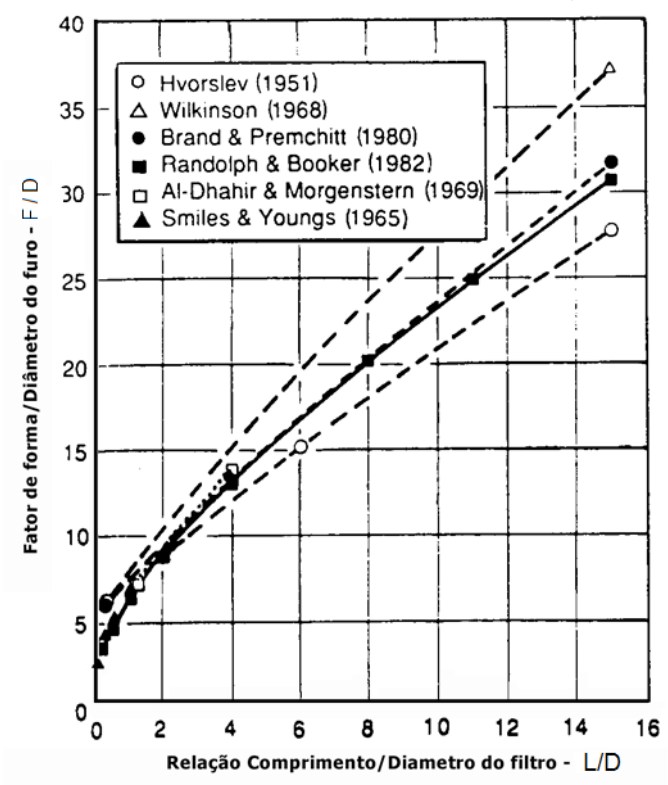

Figura 5. Proposições para o Fator F (Tavenas et al., 1990). 
$k=\frac{q \cdot \ln \left[\frac{m \cdot L}{D}+\sqrt{\left.1+\left(\frac{m \cdot L}{D}\right)^{2}\right]}\right.}{2 \cdot \pi \cdot L \cdot H c}$

$$
k=\frac{d^{2} \cdot \ln \left[\frac{m \cdot L}{D}+\sqrt{\left.1+\left(\frac{m \cdot L}{D}\right)^{2}\right]}\right.}{8 \cdot L \cdot\left(t_{2}-t_{1}\right)} \cdot \ln \frac{H_{1}}{H_{2}}(7)
$$

As equações originalmente desenvolvidas por Hvorslev (1951) para a interpretação de ensaios com piezômetros correspondiam à condição de solo abaixo do nível d'água. A utilização destas equações para o solo não saturado é uma aproximação sugerida por Daniel (1989), considerando " $\mathrm{H}$ " como a diferença de altura entre o nível d'água dentro do piezômetro e a metade da altura do filtro. Além disso, a influência da sucção do solo no gradiente hidráulico não é considerada. Para tal, quando da montagem do ensaio e expansão da bentonita, inicia-se a introdução de água dentro do piezômetro para a saturação. A realização deste procedimento torna o ensaio mais rápido, ou seja, a saturação ocorre em tempos mais reduzidos.

Uma característica fundamental dos ensaios de condutividade hidráulica com piezômetros é o elevado tempo de estabilização das leituras de vazão, quando o ensaio é realizado na modalidade de carga hidráulica constante. No caso de solos saturados, vários autores recomendam a utilização de uma técnica de extrapolação da vazão para o tempo infinito, desenvolvida por Gibson (1963) apresentada por Tavenas et al. (1986).

A utilização dessa mesma técnica de extrapolação de resultados para o caso de solos não saturados foi sugerida por Stephens \& Neumann (1982), O principal fenômeno relacionado à variação de vazão com o tempo é a diminuição do gradiente hidráulico médio com o avanço da frente de saturação. Estas equações podem ser utilizadas nas três zonas de ensaio: zona 1, onde o solo está não saturado; zona 2, o solo está saturado pela ação da capilaridade e zona 3, onde o solo está abaixo do nível d'água. Esses autores também discutem a utilização da extrapolação da curva vazão versus inverso da raiz quadrada do tempo para estimativa da vazão estabilizada, no caso de solos não saturados.

\section{ÁREA DE ESTUDO}

A cidade de Santa Maria está situada no centro geográfico do Estado do Rio Grande do Sul, entre as coordenadas 53'19'32' e $54^{\circ} 19^{\prime} 32^{\prime \prime}$ longitude oeste, e $29^{\circ} 20^{\prime} 28^{\prime \prime}$ e $30^{\circ} 00^{\prime} 16^{\prime}$ " latitude sul. A área do município compreende aproximadamente $1.780 \mathrm{~km}^{2}$ e está situado a $290 \mathrm{~km}$ da capital do estado Porto Alegre (Figura 6). Segundo Maciel Filho (1990), o relevo da região de Santa Maria apresenta três feições bem distintas: a primeira é das planícies aluviais, modeladas em sedimentos quaternários, com uma topografia plana e sujeita a inundações; a segunda corresponde a área de colinas alongadas, com uma topografia suavemente ondulada, modeladas em rochas sedimentares triássicas e a terceira, composta por terrenos com declives superiores a $15 \%$, formando patamares, que correspondem às Formações Caturrita, Botucatu e Serra Geral.
Em Santa Maria, segundo Sartori (2009), ocorrem sete unidades estratigráficas que são: Formação Sanga do Cabral (correspondente a porção fluvial da antiga Formação Rosário do Sul), Formação Santa Maria, Formação Caturrita, Formação Botucatu e Formação Serra Geral. Sobre estas encontram-se Aluviões e Terraços Fluviais que são unidades mais recentes.

Maciel Filho em 1990 elaborou a Carta Geotécnica de Santa Maria, utilizando como base a classificação estratigráfica de Bortoluzzi (1974), e considerando o comportamento geomecânico e hidrogeológico das rochas e depósitos superficiais. O autor dividiu a área urbana de Santa Maria nas seguintes unidades geotécnicas: Riólito Serra Geral, Basaltos e Diabásio Serra Geral, Arenito Botucatu, Formação Caturrita, Formação Santa Maria exceto arenito basal, Arenito Basal Santa Maria e Formação Rosário do Sul. 


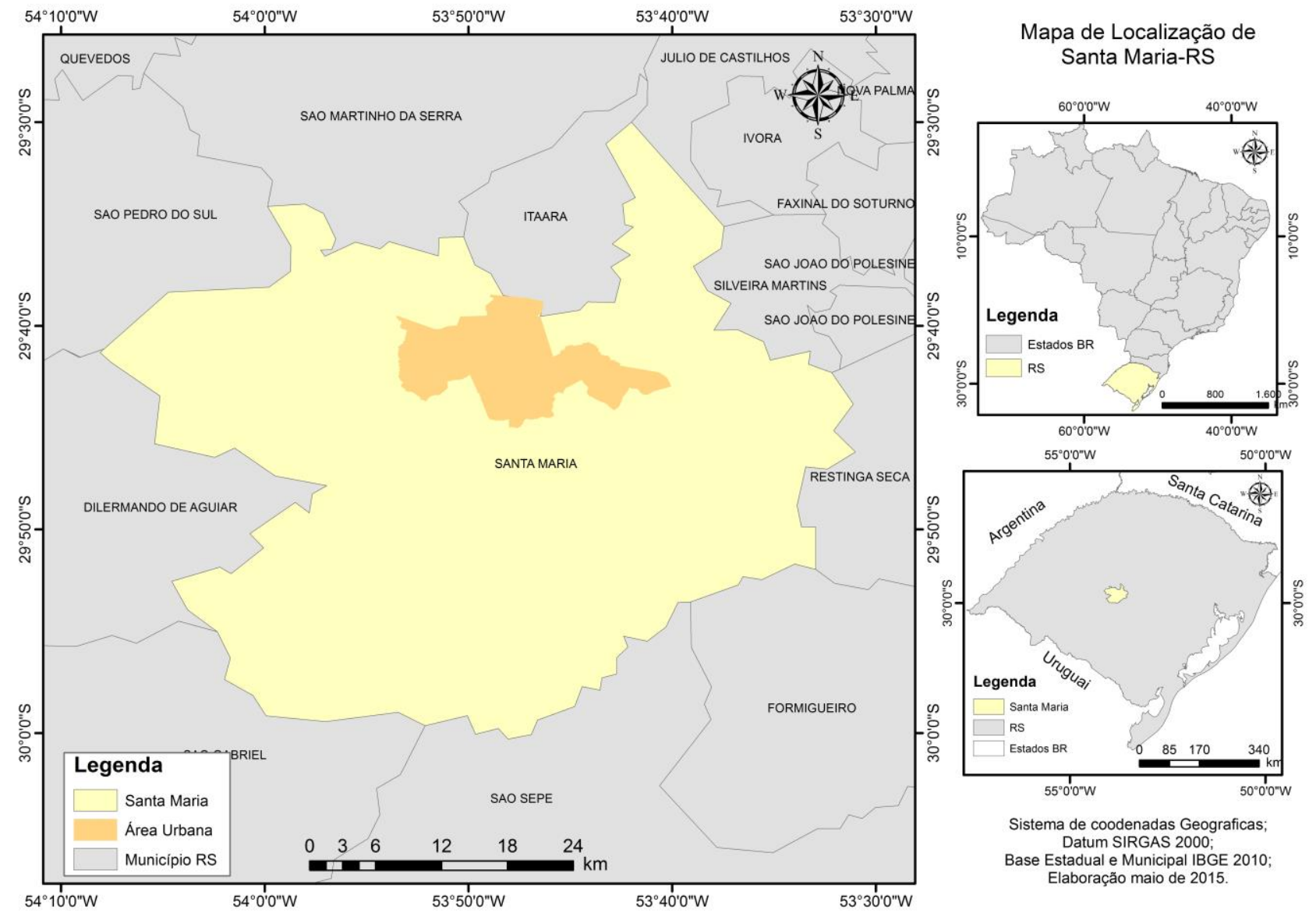

Figura 6 - Localização do município de Santa Maria (Figura elaborada Sccoti, A.A.).

Tabela 1. Unidades Sedimentares da Carta Geotécnicas de Santa Maria (Maciel Filho, 1990).

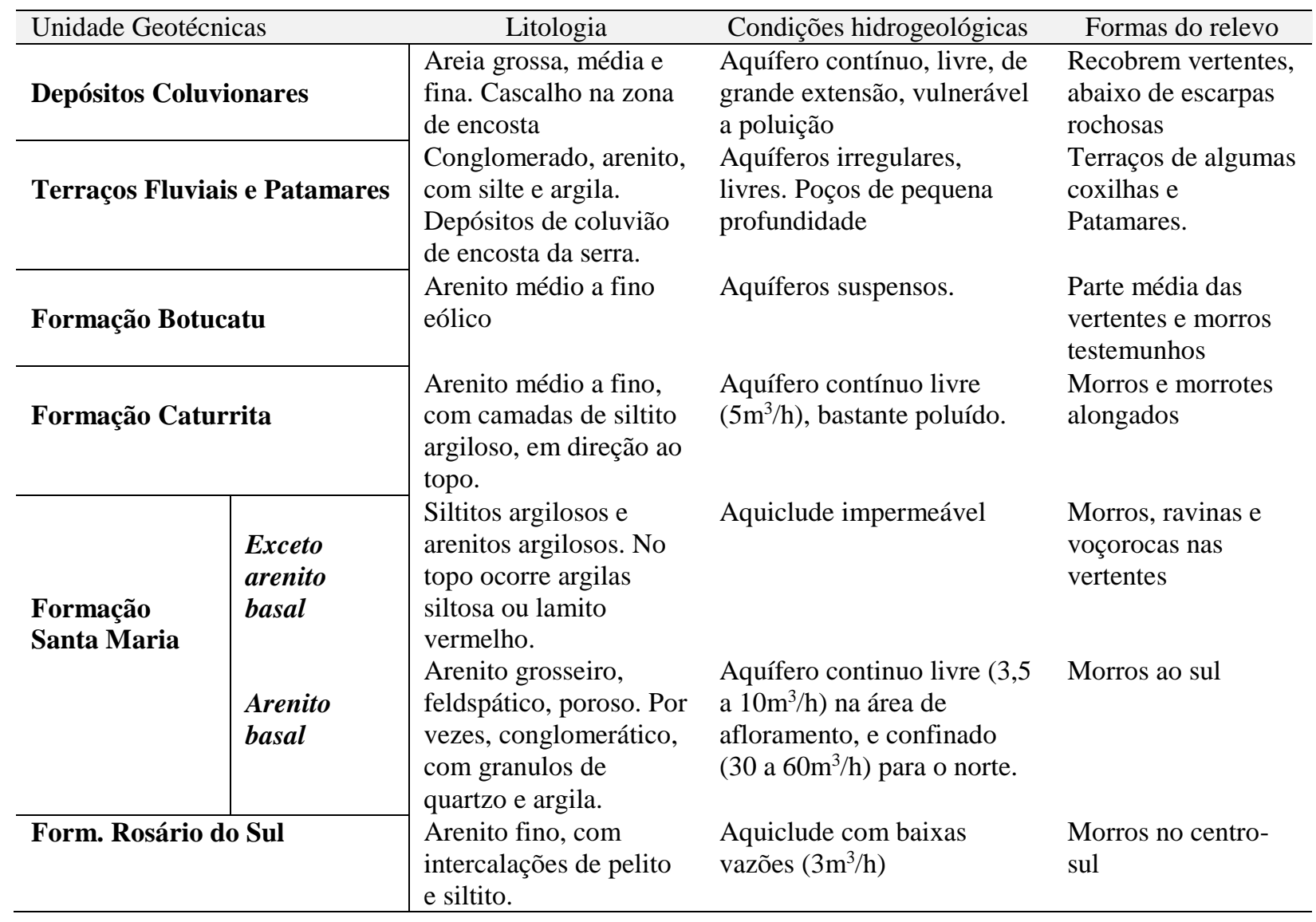


As Formações superficiais como os solos transportados que recobrem as unidades mais antigas foram denominados de Depósitos Coluvionares, Depósitos Fluviais de Várzea e Depósitos Fluviais de Terraço.

A tabela 1 resume as principais características das Unidades Geotécnicas sedimentares, com relação a composição dos materiais; o comportamento hidrológico e as formas principais de relevo onde ocorrem.

A escolha dos locais para a execução dos ensaios de condutividade hidráulica foi definida com base na carta das Unidades Geotécnicas de Maciel Filho (1990). Primeiramente buscou-se identificar as Unidades em campo, verificando se as características morfológicas e geológicas são semelhantes às descritas nos levantamentos, mapas e cartas consultadas no estudo de escritório. Foram escolhidos perfis em afloramentos de rochas sedimentares e de depósitos superficiais que melhor descrevem as características geológicas das formações, dando preferência a locais de fácil acesso.

A tabela 2 apresenta a identificação dos locais onde foram realizados os ensaios de condutividade hidráulica, com referência à Unidade Geotécnica a que pertencem. Foram avaliadas seis unidades geotécnicas: Formação Rosário do Sul (ROS); Formação Santa Maria Arenito Basal (SMP); Formação Santa Maria Exceto Arenito Basal (SMA); Formação Caturrita (CAT); Formação Botucatu (BOT); Depósitos Coluvionares (DCO) e Depósitos Fluviais de Várzea (DFL). No total foram vinte e quatro pontos ensaiados, representados em sua maioria na figura 7. Alguns locais onde foram executados os ensaios (perfis típicos) estão localizados fora da área abrangida pela Carta Geotécnica de Santa Maria, porém optouse por incluí-los nesta pesquisa, pois apresentam características que possibilitaram identificar as Unidades Geotécnicas a que pertencem e estão em continuidade com área estudada.

Tabela 2 - Identificação dos perfis típicos estudados.

\begin{tabular}{|c|c|c|c|c|}
\hline \multirow{2}{*}{$\begin{array}{c}\text { Unidades } \\
\text { Geotécnicas } \\
\end{array}$} & \multirow[t]{2}{*}{ Símbolo } & \multirow[t]{2}{*}{ Localização } & \multicolumn{2}{|c|}{ Coordenadas UTM } \\
\hline & & & Leste & Sul \\
\hline \multirow[t]{3}{*}{$\begin{array}{l}\text { Depósitos } \\
\text { Fluviais }\end{array}$} & $\begin{array}{l}\text { DFL1 } \\
\text { DFL2 } \\
\text { DFL3 }\end{array}$ & $\begin{array}{c}\text { Parque de Manutenção, rua } \\
\text { Venâncio Aires }\end{array}$ & 225023 & 6711912 \\
\hline & DFL4 & \multirow{2}{*}{ BR 287} & 222041 & 6712048 \\
\hline & DFL5 & & 221852 & 6712122 \\
\hline \multirow{2}{*}{$\begin{array}{c}\text { Depósito } \\
\text { Coluvionar }\end{array}$} & DCO1 & Av. João Luiz Pozzobon & 230540 & 6711954 \\
\hline & $\mathrm{DCO} 2$ & BR 158, Vila Bilibiu & 228650 & 6712839 \\
\hline \multirow[t]{2}{*}{ Botucatu } & BOT1 & Rua Silva Jardim & 229021 & 6713250 \\
\hline & BOT2 & BR 158, Garg.do Diabo & 231433 & 6715515 \\
\hline \multirow[t]{2}{*}{ Caturrita } & CAT1 & Av. João Luiz Pozzobon & 230563 & 6712045 \\
\hline & CAT2 & Trevo BR 158/BR 287 & 229939 & 6710990 \\
\hline \multirow[t]{3}{*}{$\begin{array}{l}\text { Santa Maria } \\
\quad \text { Exceto } \\
\text { Arenito Basal }\end{array}$} & $\begin{array}{l}\text { SMA1 } \\
\text { SMA2 } \\
\text { SMA3 }\end{array}$ & $\begin{array}{l}\text { Central de Tratamento de } \\
\text { Resíduos da Caturrita }\end{array}$ & 222278 & 6715621 \\
\hline & SMA4 & Trevo BR158/BR 287 & 229801 & 6711060 \\
\hline & $\begin{array}{l}\text { SMA5 } \\
\text { SMA6 }\end{array}$ & Campus / UFSM & 236855 & 6702853 \\
\hline \multirow{3}{*}{$\begin{array}{c}\text { Santa Maria } \\
\text { Arenito Basal }\end{array}$} & SMP1 & Estrada Pains & 238595 & 6709564 \\
\hline & SMP2 & BR 392 & 229875 & 6706411 \\
\hline & SMP3 & São Valentin & 789137 & 6703213 \\
\hline \multirow{4}{*}{$\begin{array}{l}\text { Formação } \\
\text { Rosário do } \\
\text { Sul }\end{array}$} & ROS1 & \multirow{4}{*}{$\begin{array}{c}\text { Aterro de Resíduos } \\
\text { Industriais e Perigosos, Passo } \\
\text { da Capivara }\end{array}$} & \multirow{4}{*}{233047} & \multirow{4}{*}{6702853} \\
\hline & ROS2 & & & \\
\hline & ROS3 & & & \\
\hline & ROS4 & & & \\
\hline
\end{tabular}




\section{Localização dos pontos amostrados: Carta Geotécnica de Santa Maria}

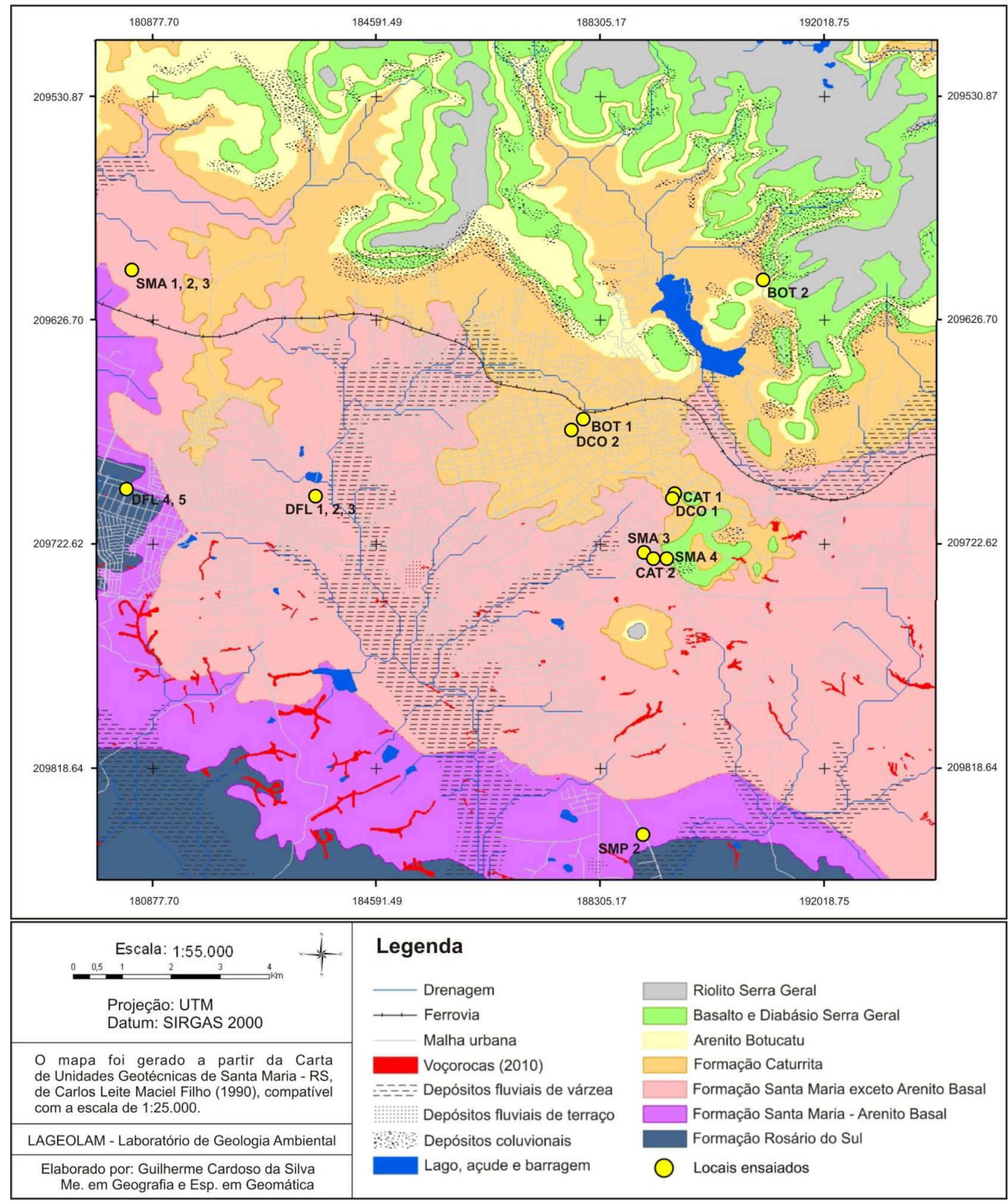

Figura 7. Localização dos perfis ensaiados na Carta Geotécnica de Santa Maria de Maciel Filho, 1990 (Figura elaborada por Guilherme Cardoso da Silva).

Além dos ensaios de condutividade hidráulica foram realizados, em laboratório, os seguintes ensaios: determinação da massa específica real dos grãos (NBR 6508/84), limite de plasticidade (NBR 7180/84), limite de liquidez (NBR 6459/84) e análise granulométrica por peneiramento e sedimentação (NBR 7181/84). As amostras para a realização dos ensaios de laboratório foram coletadas na mesma profundidade em que foram realizados os ensaios de condutividade hidráulica. 


\section{RESULTADOS E DISCUSSÕES}

A tabela 3 apresenta os resultados dos ensaios de caracterização realizados com as amostras coletadas nos perfis típicos. Os perfis caracterizados como Depósito Fluvial da Várzea do Arroio Cadena e Ferreira apresentam texturas que variam de areias a argilas. Os resultados obtidos nos cinco perfis demonstram estas características. Os perfis DFL1 e DFL3 são areias siltosas e os perfis DFL4 e DFL5 são siltes areno-argilosos, ambos com baixa plasticidade, com fração areia superior a $50 \%$ e fração argila inferior a $16 \%$. O perfil DFL2 apresenta uma textura argilosa, com alta plasticidade, tendo uma fração argila superior a $60 \%$.

Tabela 3 - Resultados dos ensaios de massa específica real dos grãos, limites de consistência, granulometria e classificação pelo sistema unificado (ASTM, D24487-11) das unidades geotécnicas de Santa Maria.

\begin{tabular}{|c|c|c|c|c|c|c|c|c|c|c|c|}
\hline Unidades & $\begin{array}{c}\gamma^{s} \\
\left(\mathrm{KN} / \mathrm{m}^{3}\right)\end{array}$ & $\begin{array}{l}\mathrm{LL} \\
(\%)\end{array}$ & $\begin{array}{l}\mathrm{LP} \\
(\%)\end{array}$ & $\begin{array}{l}\text { IP } \\
(\%)\end{array}$ & $\begin{array}{l}\text { Pedre- } \\
\text { gulho } \\
(\%)\end{array}$ & $\begin{array}{c}\text { Areia } \\
\text { Grossa } \\
(\%)\end{array}$ & $\begin{array}{c}\text { Areia } \\
\text { Média } \\
(\%)\end{array}$ & $\begin{array}{c}\text { Areia } \\
\text { Fina } \\
(\%)\end{array}$ & $\begin{array}{l}\text { Silte } \\
(\%)\end{array}$ & $\begin{array}{c}\text { Argila } \\
(\%) \\
\end{array}$ & $\begin{array}{c}\text { Classificação } \\
\text { (ASTM, } \\
\text { 2011) }\end{array}$ \\
\hline DFL1 & 26,1 & 18 & 14 & 4 & 0 & 5 & 23 & 28 & 31 & 13 & SC-SM \\
\hline DFL2 & 25,9 & 72 & 28 & 44 & 0 & 1 & 2 & 12 & 23 & 62 & $\mathrm{CH}$ \\
\hline DFL3 & 25,7 & 23 & 18 & 5 & 0 & 2 & 11 & 67 & 8 & 12 & SC-SM \\
\hline DFL4 & 26,6 & 21 & 10 & 11 & 2 & 3 & 10 & 30 & 39 & 16 & ML \\
\hline DFL5 & 26,6 & 20 & 10 & 10 & 2 & 3 & 8 & 37 & 34 & 16 & ML \\
\hline DCO1 & 26,4 & 48 & 35 & 13 & 0 & 21 & 16 & 21 & 26 & 16 & ML \\
\hline $\mathrm{DCO} 2$ & 28,0 & 29 & 25 & 4 & 0 & 12 & 20 & 15 & 44 & 9 & ML \\
\hline BOT1 & 25,6 & 32 & 24 & 8 & 0 & 0 & 3 & 50 & 39 & 8 & ML \\
\hline BOT2 & 27,2 & 22 & N.P. & N.P. & 0 & 0 & 1 & 85 & 5 & 9 & SP-SM \\
\hline CAT1 & 26,5 & 48 & 33 & 15 & 0 & 0 & 0 & 14 & 78 & 8 & ML \\
\hline CAT2 & 26,4 & 28 & N.P & N.P & 0 & 0 & 4 & 66 & 28 & 2 & SW-SM \\
\hline SMA1 & 27,3 & 48 & 26 & 22 & 0 & 8 & 15 & 31 & 30 & 16 & CL \\
\hline SMA2 & 27,4 & 86 & 28 & 58 & 0 & 3 & 3 & 16 & 46 & 32 & $\mathrm{CH}$ \\
\hline SMA3 & 26,9 & 53 & 30 & 23 & 0 & 0 & 1 & 15 & 15 & 39 & ML \\
\hline SMA4 & 26,7 & 45 & 19 & 24 & 0 & 0 & 2 & 23 & 53 & 22 & CL \\
\hline SMA5 & 27,1 & 51 & 25 & 36 & 0 & 2 & 2 & 9 & 45 & 44 & $\mathrm{CH}$ \\
\hline SMA6 & 27,5 & 73 & 34 & 39 & 0 & 0 & 1 & 7 & 42 & 50 & $\mathrm{CH}$ \\
\hline SMP1 & 30,4 & N.P. & N.P. & N.P. & 2 & 48 & 24 & 11 & 9 & 6 & SP-SM \\
\hline SMP2 & 27,5 & 32 & 24 & 8 & 0 & 3 & 50 & 20 & 20 & 7 & ML \\
\hline SMP3 & 26,6 & 34 & 19 & 15 & 0 & 0 & 13 & 54 & 16 & 17 & $\mathrm{SC}$ \\
\hline ROS1 & 27,3 & N.P. & N.P. & N.P. & 0 & 18 & 46 & 10 & 20 & 6 & SP-SM \\
\hline ROS2 & 27,6 & N.P. & N.P. & N.P. & 0 & 14 & 38 & 9 & 35 & 4 & SP-SM \\
\hline ROS3 & 27,2 & N.P. & N.P. & N.P. & 0 & 10 & 45 & 19 & 20 & 8 & SP-SM \\
\hline ROS4 & 26,9 & N.P. & N.P. & N.P. & 0 & 8 & 43 & 19 & 24 & 6 & SP-SM \\
\hline
\end{tabular}

Legenda: $\gamma_{\mathrm{s}}=$ peso específico real dos grãos; LL - Limite de Liquidez; LP - Limite de Plasticidade; IP - Índice de Plasticidade; N.P. - Não plástico.

Os Depósitos Coluvionares foram estudados em dois perfis típicos. Ambos são constituídos por uma matriz, classificada geotecnicamente como silte (ML) e apresentam uma quantidade expressiva de fragmentos de arenito e basalto em tamanhos variados, baixa a média 
plasticidade e contendo uma quantidade significativa de matéria orgânica, como o perfil DCO1.

Nos perfis da Formação Botucatu nota-se a presença significativa da fração areia fina $(50 \%$ a $85 \%$ ), sendo que o perfil BOT2 apresenta-se mais silicificado e não plástico classificado como areia mal graduada (SP-SW). Já o perfil BOT1 apresenta-se uma quantidade maior finos, baixa plasticidade, sendo classificado como silte (ML). Como este perfil (BOT1) está muito próximo do contato com a Formação Caturrita (arenito fino) e apresenta uma grande quantidade de finos (silte), o que não é comum na Formação Botucatu; sugere-se estudos complementares em outros afloramentos típicos para um melhor entendimento dos resultados.

Os perfis da Formação Caturrita apresentaram uma diferenciação quanto à granulometria e plasticidade. O perfil CAT1 é de constituição mais fina, plástico e classificado geotecnicamente como um silte (ML). Já o perfil CAT2 é mais grosseiro, com predomínio de areia fina, não plástico, classificado com areia bem graduada com silte (SW-SM). Ambos apresentam uma fração argila inferior a $10 \%$.

A Formação Santa Maria - exceto Arenito Basal apresenta uma predominância da fração fina (46\% a 92\%), com média a alta plasticidade (LL>45\%), sendo classificada geotecnicamente como argilas de baixa (CL) e alta plasticidade $(\mathrm{CH})$. Nos perfis desta Formação, Emmer (2004) e Pinto (2005), identificaram argilominerais dos grupos ilitamontmorilonita (interestratificados).

$\mathrm{Na}$ Unidade Geotécnica Arenito Basal da Formação Santa Maria (parte inferior da sequência) verificou-se o predomínio da fração areia (67 a 87\%), com comportamento não plástico ou de baixa plasticidade, classificadas geotecnicamente como areias mal graduadas com silte ou argila e siltes arenosos.

$\mathrm{Na}$ sequência sedimentar mais antiga, Formação Rosário do Sul, foram realizados quatro ensaios localizados na área do aterro de resíduos perigosos e industriais. Nesta unidade, a fração argila é inferior a $8 \%$, caracterizando um comportamento não plástico, sendo classificada como areias mal graduadas com silte. Os valores das frações granulométricas e sua distribuição (Tabela 3) refletem uma grande variabilidade nas quantidades relativas às frações areia, silte e argila o que deve ser atribuído ao paleoambiente gerador das Formações geológicas sedimentares na região de Santa Maria.

Os ensaios de condutividade hidráulica (k) foram realizados em diferentes profundidades, em função do acesso aos perfis típicos. Nos ensaios mais profundos, realizados em furos de sondagem tipo SPT $(\operatorname{ROS} 1,2,3$ e 4) a altura do filtro granular foi de $1,0 \mathrm{~m}$. Já nos outros ensaios realizados em profundidades menores, a altura do filtro variou de 0,15 e $0,30 \mathrm{~m}$.

As considerações e fórmulas adotadas para o cálculo da condutividade hidráulica estão apresentadas nas equações 6 e 7. Os resultados dos ensaios e respectivas profundidades são apresentados na tabela 4. A Figura 8 apresenta graficamente a amplitude de todos os valores obtidos de condutividade hidráulica na região de Santa Maria.

Os Depósitos Fluviais do Arroio Cadena e Ferreira são caracterizados pela sua textura arenosa e argilosa em porções variáveis Esta diferenciação granulométrica se verificou nos ensaios de condutividade hidráulica. $\mathrm{O}$ perfil argiloso (DFL2) apresentou um comportamento menos permeável que os perfis arenosos (DFL1, DFL2, DFL4 e DFL5).

Os perfis localizados em depósitos coluvionares apresentaram valores médios de coeficiente de condutividade hidráulica (na ordem de $10^{-5} \mathrm{~m} / \mathrm{s}$ ), sendo considerados os mais elevados (permeáveis) dentre as unidades estudadas pois são materiais porosos, mesmo que neles predomine a fração argila. Os valores obtidos se assemelham aos encontrados na bibliografia, como por exemplo, nos estudos realizados por Perazzolo (2003) em colúvios argilosos nas cidades de Bento Gonçalves e Caxias do Sul onde obteve valores de condutividade hidráulica entre $1,9 \times 10^{-6} \mathrm{~m} / \mathrm{s}$ a $8,3 \times 10^{-7} \mathrm{~m} / \mathrm{s}$. Da mesma forma em depósitos coluvionares na região de Santa Cruz do Sul, Pinheiro (2000) e Pinheiro et al. (2012), encontraram valores de condutividade hidráulica da ordem de $10^{-5} \mathrm{~m} / \mathrm{s}$. Valores superiores a estes foram obtidos em solos coluvionares em São Vendelino e Três Coroas na Serra do Rio Grande do Sul (Martinello, 2006; Nichel, 2011). 
Tabela 4 - Resultados dos ensaios com piezômetros escavados para determinação do k (in situ).

\begin{tabular}{|c|c|c|c|c|c|}
\hline $\begin{array}{c}\text { Unidade } \\
\text { Geotécnica }\end{array}$ & Ensaios & $\begin{array}{l}\text { Prof. } \\
(\mathbf{m})\end{array}$ & L/D & $\begin{array}{c}\mathbf{k} \\
(\mathbf{m} / \mathbf{s}) \\
\end{array}$ & $\begin{array}{c}\text { Valor médio } \\
(\mathrm{m} / \mathrm{s})\end{array}$ \\
\hline \multirow{5}{*}{$\begin{array}{l}\text { Depósitos } \\
\text { Fluviais }\end{array}$} & DFL1 & 1,10 & 3,5 & $1,3 \times 10^{-5}$ & \multirow{5}{*}{$1,1 \times 10^{-5}$} \\
\hline & DFL2 & 1,00 & 3,5 & $3,3 \times 10^{-7}$ & \\
\hline & DFL3 & 1,00 & 3,5 & $2,9 \times 10^{-5}$ & \\
\hline & DFL4 & 1,80 & 3,5 & $5,7 \times 10^{-6}$ & \\
\hline & DFL5 & 1,50 & 3,5 & $4,5 \times 10^{-6}$ & \\
\hline \multirow{2}{*}{ Depósito Coluvionares } & DCO1 & 0,50 & 5 & $6,9 \times 10^{-5}$ & \multirow{2}{*}{$4,4 \times 10^{-5}$} \\
\hline & $\mathrm{DCO} 2$ & 4,0 & 5 & $1,9 \times 10^{-5}$ & \\
\hline \multirow{2}{*}{ Botucatu } & BOT1 & 0,65 & 2 & $5,3 \times 10^{-6}$ & \multirow{2}{*}{$2,8 \times 10^{-6}$} \\
\hline & BOT2 & 0,50 & 2 & $4,4 \times 10^{-7}$ & \\
\hline \multirow{2}{*}{ Caturrita } & CAT1 & 0,45 & 2 & $1,9 \times 10^{-6}$ & \multirow{2}{*}{$1,5 \times 10^{-6}$} \\
\hline & CAT2 & 1,0 & 3,5 & $1,0 \times 10^{-6}$ & \\
\hline \multirow{6}{*}{$\begin{array}{c}\text { Santa Maria } \\
\text { Exceto Arenito Basal }\end{array}$} & SMA1 & 1,5 & 3,5 & $6,0 \times 10^{-8}$ & \multirow{6}{*}{$2,3 \times 10^{-8}$} \\
\hline & SMA2 & 1,75 & 3,5 & $2,3 \times 10^{-8}$ & \\
\hline & SMA3 & 1,0 & 3,5 & $7,2 \times 10^{-9}$ & \\
\hline & SMA4 & 1,0 & 3,5 & $1,0 \times 10^{-8}$ & \\
\hline & SMA5 & 1,3 & 3,5 & $8,8 \times 10^{-9}$ & \\
\hline & SMA6 & 0,4 & 3,5 & $3,1 \times 10^{-8}$ & \\
\hline \multirow{3}{*}{$\begin{array}{c}\text { Santa Maria } \\
\text { Arenito Basal }\end{array}$} & SMP1 & 0,5 & 3,5 & $7,0 \times 10^{-6}$ & \multirow{3}{*}{$2,9 \times 10^{-6}$} \\
\hline & SMP2 & 0,85 & 2,5 & $6,5 \times 10^{-7}$ & \\
\hline & SMP3 & 1,0 & 3,5 & $1,2 \times 10^{-6}$ & \\
\hline \multirow{4}{*}{ Rosário do Sul } & ROS1 & 6,65 & 10 & $2,6 \times 10^{-7}$ & \multirow{4}{*}{$2,5 \times 10^{-6}$} \\
\hline & ROS2 & 6,50 & 10 & $3,6 \times 10^{-6}$ & \\
\hline & ROS3 & 6,82 & 10 & $2,7 \times 10^{-6}$ & \\
\hline & ROS4 & 6,57 & 10 & $3,6 \times 10^{-6}$ & \\
\hline
\end{tabular}

A Formação Botucatu apresentou valores médios de coeficiente de condutividade hidráulica na ordem de 2,8 x $10^{-6} \mathrm{~m} / \mathrm{s}$, semelhantes aos encontrados por Bortoli (1999) em um solo de alteração desta mesma Formação no município de São Sebastião do Caí (k = 1,8 x 10 $\left.10^{-6} \mathrm{~m} / \mathrm{s}\right)$. Já Pinheiro (2000) ao estudar os arenitos intertraps da Formação Botucatu na cidade de Santa Cruz do Sul obteve valores de permeabilidade um pouco menores $\left(\mathrm{k}=6,0 \times 10^{-7} \mathrm{~m} / \mathrm{s}\right)$.

Os resultados obtidos para os perfis da Formação Caturrita foram similares ao encontrados para a Formação Botucatu. A condutividade hidráulica obtida foi na ordem de
$10^{-6} \mathrm{~m} / \mathrm{s}$.

Os valores mais baixos de condutividade hidráulica obtidos foram para a parte superior da Formação Santa Maria, Unidade Geotécnica denominada de Formação Santa Maria - Exceto Arenito Basal que foram da ordem de $6,0 \times 10^{-8}$ a $7,2 \times 10^{-9} \mathrm{~m} / \mathrm{s}$. Nesta Formação predominam materiais mais finos (siltes e argilas) em relação à fração areia o que reflete nos valores de baixa condutividade hidráulica obtida nos ensaios (Figura 8). Pinheiro et al (2012) encontraram valores de condutividade entre $5,2 \times 10^{-8} \times$ a 4,1 x $10^{-9} \mathrm{~m} / \mathrm{s}$ para esta Formação em estudos de estabilidade de encostas na cidade de Santa Cruz do Sul. 


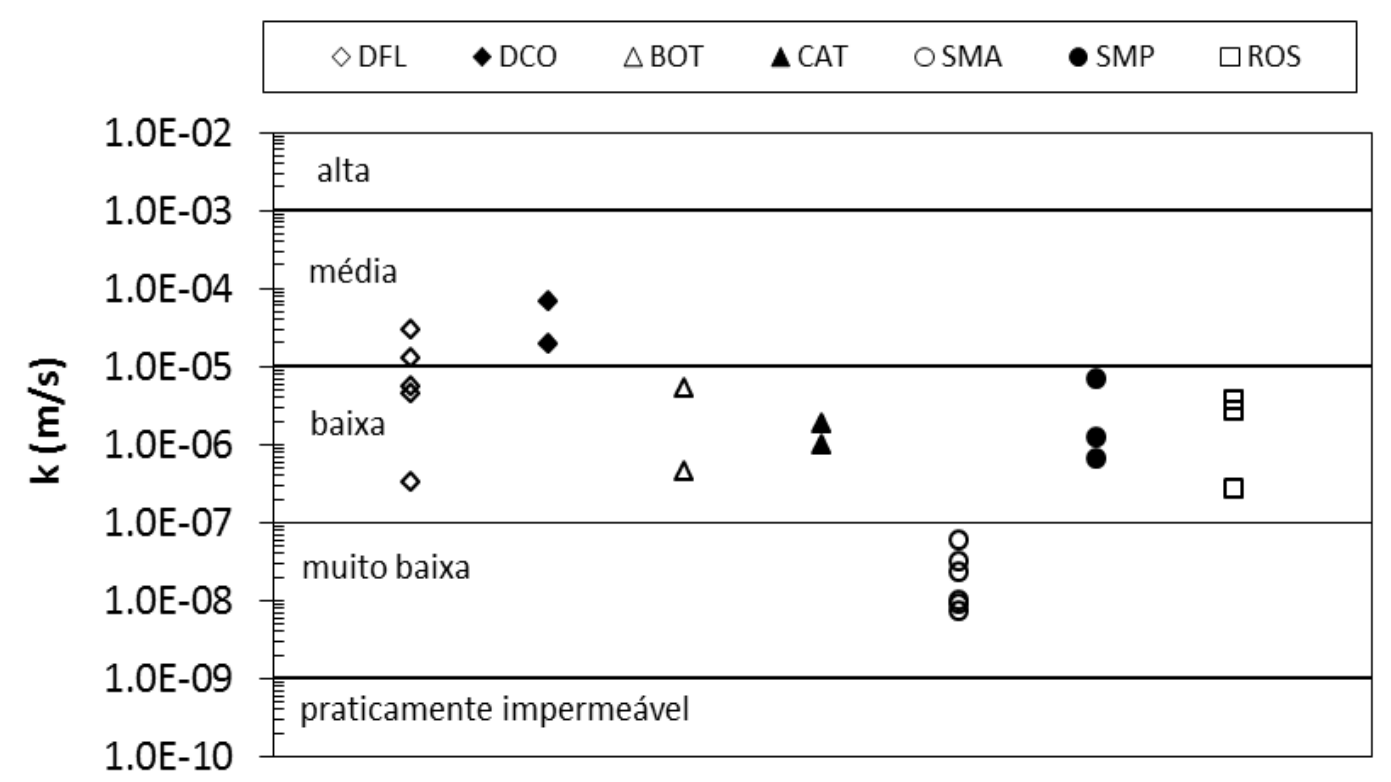

Figura 8. Representação gráfica dos resultados dos ensaios de condutividade hidráulica.

Já para o Arenito Basal da Formação Santa Maria, onde predominam as frações areia grossa/média sobre a fina, os resultados dos ensaios apresentam uma condutividade hidráulica entre $1,2 \times 10^{-6}$ (mais permeáveis) a $7,0 \times 10^{-6} \mathrm{~m} / \mathrm{s}$. O menor valor de condutividade desta unidade foi obtido no perfil SMP6, localizado num material de alteração (solo saprolítico) onde predomina a areia média em relação a fração mais grossa.

Os valores obtidos para os perfis da Formação Rosário do Sul foram similares aos da Formação Santa Maria - Arenito Basal, com uma condutividade hidráulica da ordem de 2,5 x $10^{-6} \mathrm{~m} / \mathrm{s}$, exceto para o perfil ROS1 que apresentou um valor inferior de condutividade hidráulica.

As figuras 9 e 10 apresentam a correlação entre os finos (silte + argila) e a fração areia e os valores de condutividade hidráulica. Verifica-se uma tendência de redução do valor da condutividade hidráulica com a elevação da porcentagem de finos, da mesma forma ocorre um acréscimo da condutividade com o aumento da fração areia sendo que, que esta correlação com a fração areia é mais significativa.

Finos (\%)

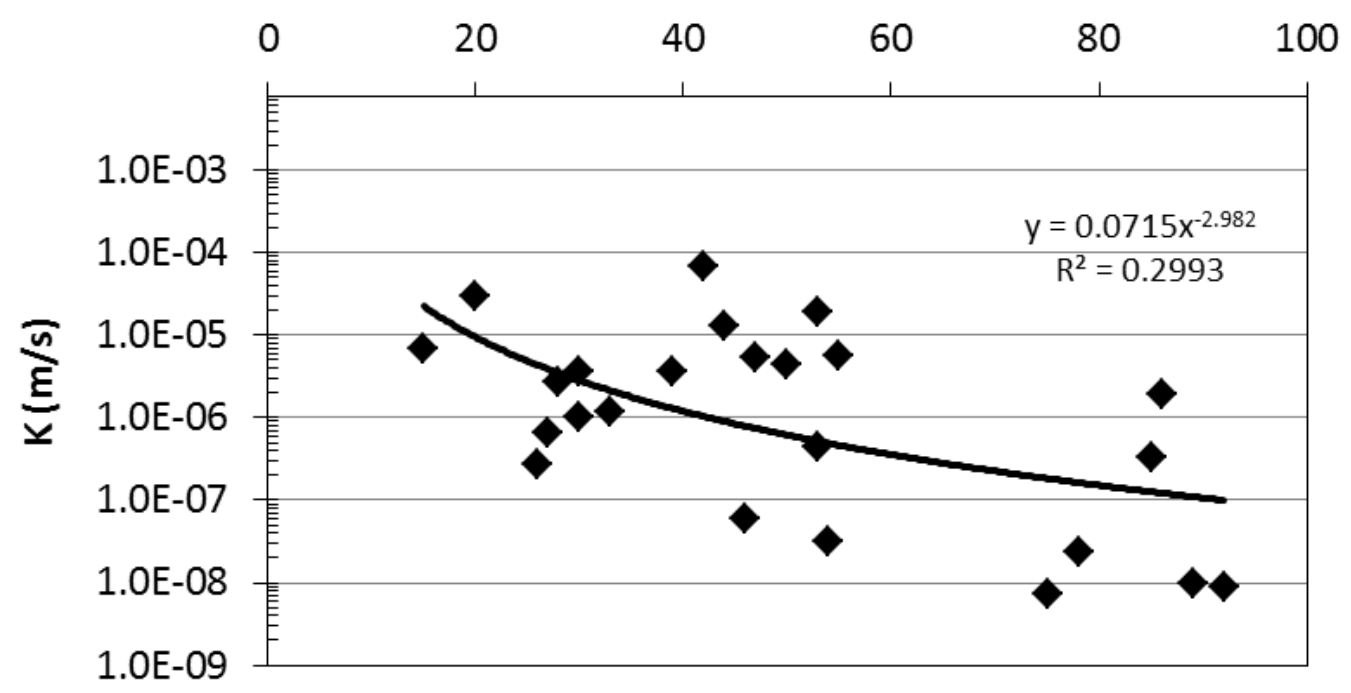

Figura 9. Variação da condutividade hidráulica com a fração fina (silte + argila). 


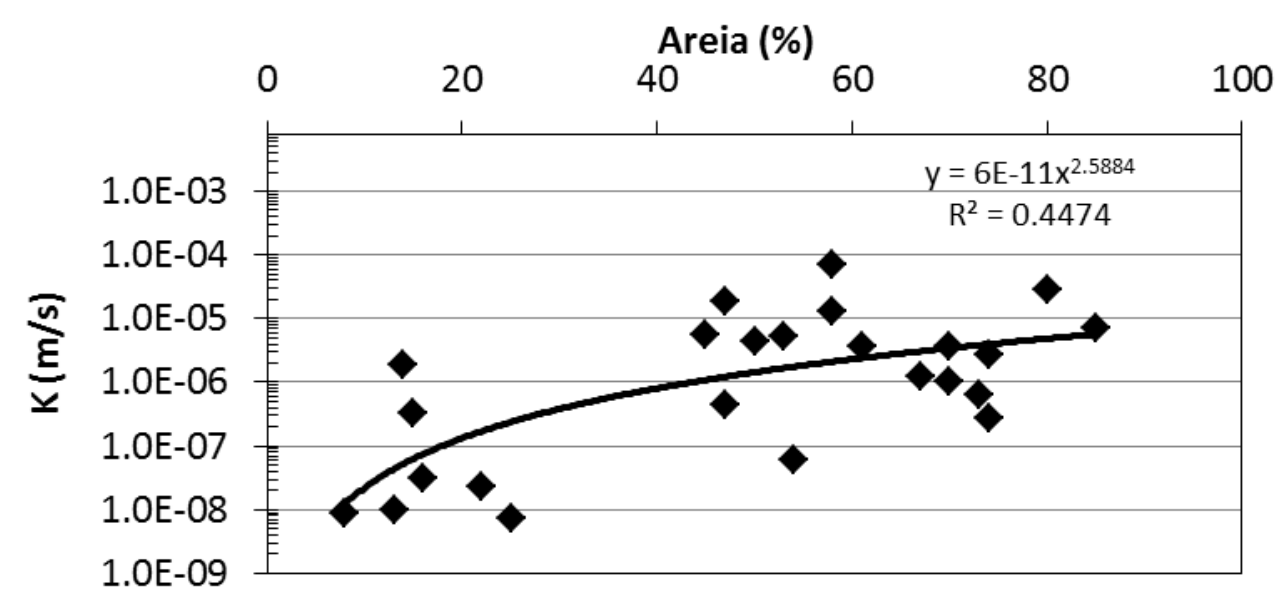

Figura 10. Variação da condutividade hidráulica com a fração areia total.

\section{CONCLUSÕES}

Os ensaios de condutividade hidráulica com piezômetros realizados nas Unidades Geotécnicas de Santa Maria mostraram resultados satisfatórios em relação ao tempo de ensaio e valores obtidos, confirmando e quantificando as informações contidas no trabalho de Maciel Filho (1990). Esta técnica mostrou-se eficiente pois considera a utilização de um filtro granular (L/D) equivalente a um elipsóide e adota a solução da equação analítica de Laplace para o fator de forma (F), podendo ser realizado desde profundidades pequenas, até profundidades mais elevadas em furos de sondagem.

Os Depósitos Coluvionares (COL) e os Fluviais (DFL), foram as unidades que apresentaram valores de condutividade média, variando de 1 a 4,4 x $10^{-5} \mathrm{~m} / \mathrm{s}$, sendo considerados os materiais mais permeáveis da região de Santa Maria. Vale ressaltar que a presença de materiais mais argilosos nesta unidade podem resultar em valores mais baixos de permeabilidade.

As Unidades Geotécnicas das Formações Botucatu, Caturrita, Santa Maria - Arenito Basal e Rosário do Sul apresentaram valores médios de condutividade hidráulica $\left(1,5 \times 10^{-6}\right.$ a $2,9 \times 10^{-6} \mathrm{~m} / \mathrm{s}$ ). Já a Unidade Formação Santa Maria - Exceto Arenito Basal apresentou baixa condutividade hidráulica, com valores em torno de $2,2 \times 10^{-8} \mathrm{~m} / \mathrm{s}$ por ser composta de materiais siltosos e argilosos.

As Unidades Geotécnicas mostraram diferentes valores de condutividade hidráulica o que se dá principalmente pela composição granulométrica, cimentação e estruturas sedimentares presentes. Isto significa, em termos ambientais e hidrogeológicos, que a infiltração de águas nos aquíferos apresenta diferentes condições de recarga, o que deve ser considerado na avaliação e gestão das reservas de águas subterrâneas da região.

\section{REFERÊNCIAS}

ABGE - ASSOCIAÇÃO BRASILEIRA DE GEOLOGIA DE ENGENHARIA E AMBIENTAL. Ensaios de permeabilidade em solos - orientações para sua execução no campo. 4a. Ed. São Paulo, 80 p., 2013.

ASSOCIAÇÃO BRASILEIRA DE NORMAS TÉCNICAS. NBR 6508: Grãos de solos que passam na peneira de $\mathbf{4 . 8}$ mm - Determinação da massa específica. Rio de Janeiro, $1984.8 \mathrm{p}$.

ASSOCIAÇÃO BRASILEIRA DE NORMAS TÉCNICAS. NBR 7181: Solo - Análise granulométrica. Rio de Janeiro, $1984.13 \mathrm{p}$.

ASSOCIAÇÃO BRASILEIRA DE NORMAS TÉCNICAS. NBR 6459: Solo - Determinação do limite de liquidez Método de ensaio. Rio de Janeiro, 1984. 6 p.

ASSOCIAÇÃO BRASILEIRA DE NORMAS TÉCNICAS. NBR 7180: Solo - Determinação do limite de Plasticidade - Método de ensaio. Rio de Janeiro, 1984. 3 p.

ASTM D 2487-11. Standard Practice for Classification of Soils for Engineering Purposes (Unified Soil Classification
System), ASTM International, West Conshohocken, PA, 2011.

BORTOLI, C. R. Estudo numérico-experimental da condutividade hidráulica saturada/não saturada de um solo estruturado. Porto Alegre, 1999. 121 p. Dissertação (Mestrado em Engenharia) - Escola de Engenharia, Universidade Federal do Rio Grande do Sul.

BORTOLUZZI, C.A. Contribuição à Geologia da região de Santa Maria, Rio Grande do sul, Brasil. Pesquisas, v. 4, n. 1, p. 7-86.1974.

BRAND, E. W. \& PREMCHITT, J. Shape factors of cylindrical piezometers. Géotechnique, v. 30, n. 4, p 369-384, 1980.

CHAPUIS, R.P. Shape factors for permeability tests in boreholes and piezometers. Ground Water, v. 37, n. 5, p. 647-654, 1989.

DANIEL, D.E. Predicting hydraulic conductivity of clay liners. Journal of Geotechnical Engineering, v. 21, n. 2, p. 285300, 1989. 
DANIEL, D.E. State-of-the-art: laboratory hydraulic conductivity tests for saturated soils. In: HYDRAULIC CONDUCTIVITY AND WASTE CONTAMINANT TRANSPORT IN SOIL.ASTM STP 1142, Proceedings...Philadelphia: David E. Daniel and Stephen J. Tratwein, Eds., ASTM, 1994, p. 30-78.

DEGROOT, D.J \& LUTENEGGER, A.J. A comparison between field and laboratory measurements of hydraulic conductivity in a varved clay. In: HYDRAULIC CONDUCTIVITY AND WASTE CONTAMINANT TRANSPORT IN SOIL, ASTM STP 1142, Proceedings...Philadelphia: David E. Daniel and Stephen J. Tratwein, Eds., ASTM, 1994, p. 300-317.

EMMER, R. Implantação do campo experimental de engenharia geotécnica da UFSM. Santa Maria, 2004. 176 p. Dissertação (Mestrado em Engenharia) - Universidade Federal de Santa Maria.

FIORI, J.P.O.; CAMPOS, J.E.G.; ALMEIDA L. Variabilidade da condutividade hidráulica das principais classes de solos do estado de Goiás. Geociências, v. 29, n. 2, p. 229-235, 2010.

GIBSON, R.E. An analysis of system flexibility and its effects on time-lag in pore-water pressure measurements. Geotechnique, v. 13, p. 1-11, 1963.

HERZOG, B.L. Slug tests for determining hydraulic conductivity of natural geologic deposits. In: HYDRAULIC CONDUCTIVITY AND WASTE CONTAMINANT TRANSPORT IN SOIL, ASTM STP 1142, Proceedings...Philadelphia: David E. Daniel and Stephen J. Tratwein, Eds., ASTM, 1994, p. 95-110.

HVORSLEV, M.J. Time lag and soil permeabililty in ground water observations, Bulletin no. 36, Waterways Experiment Station, U.S. Army Corps of Engineers, Vicksburg, MS. 50 p, 1951.

LUMB, P. The variability of natural soils. Canadian Geotechnical Journal, v. 3, n. 2, p. 74-97, 1966.

MACIEL FILHO, C.L. Carta geotécnica de Santa Maria. Imprensa Universitária/FINEP. UFSM, Santa Maria, 21 p. 1990.

MARTINELLO, I.A. Estudo das condicionantes hidráulicas de uma ruptura de talude em São Vendelino (RS). Porto Alegre, 2006, 160 p. Dissertação (Mestrado em Engenharia Civil -Geotecnia) - Escola de Engenharia, Universidade Federal do Rio Grande do Sul.

MESQUITA, M.G.B. \& MORAES, S.O. A dependência entre a condutividade hidráulica saturada e atributos físicos do solo. Ciência Rural, v. 34, n. 3, p. 963-969, 2004.

NAGY, L.; TABACKS, A.; HUSZÁK, T.;VARGA, G. Comparison of permeability testing methods. In: INTERNATIONAL CONFERENCE ON SOIL MECHANICS AND GEOTECHNICAL ENGINEERING, 18, 2013, Paris. Proceedings...Paris, 2013, Technical Committee 101 - Session II, 2013, p. 399-402.

NICHEL, A. Diagnóstico, monitoramento e concepção de medidas de estabilização do colúvio do $\mathbf{k m ~} 23+400$ da rodovia RS/115. Porto Alegre, 2011. 122 p. Dissertação (Mestrado em Engenharia Civil - Geotecnia) - Escola de Engenharia - Universidade Federal do Rio Grande do Sul.

OLSON, R.E. \& DANIEL, D.E. Measurement of the hydraulic conductivity of fine-grained soils. Permeability and Groundwater Contaminant Transport, ASTM STP 746, T.F. ZIMMIE AND C.O. RIGGS, Eds., American Society for Testing and Materials, Philadelphia, 1981, pp. 18-64.
PINHEIRO, R.J.B. Estudos de Alguns Casos de Instabilidade da Encosta da Serra Geral no Estado do Rio Grande do Sul. Porto Alegre, 2000, 340 p. Tese (Doutorado em Engenharia - Geotécnica), Escola de Engenharia Universidade Federal do Rio Grande do Sul.

PINHEIRO, R. J.B; NUMMER, A.V.; BRESSANI, L. A. Análise de instabilidade de uma encosta localizada na área urbana de Santa Cruz do Sul, RS. Geociências, v. 31, n. 2, p. 159-174, 2012.

PINTO, J. Estudo da condutividade hidráulica de solos para disposição de resíduos sólidos na região de Santa Maria. Santa Maria, 2005, 126 p. Dissertação (Mestrado em Engenharia Civil) - PPGEC, Universidade Federal de Santa Maria.

PERAZOLO, L. Estudo geotécnico de dois taludes da Formação Serra Geral, RS. Porto Alegre, 2003, 150 p. Dissertação (Mestrado em Engenharia) - Escola de Engenharia, Universidade Federal do Rio Grande do Sul.

RANDOLPH, M.F. \& BOOKER, J.R. Analysis of seepage into a cylindrical permeameter. INT. CONF. ON NUMERICAL METHODS IN GEOMECHANICS, 4, 1986. Edmonton. Proceedings... v. 1, n. 4, p. 349-357, 1986.

REICHARDT, K. Dinâmica da matéria e da energia em ecossistemas. 2 ed. Piracicaba: ESALQ. Depto de Física e Meteorologia, 160 p, 1996.

REICHARDT, K. A água em sistemas agrícola. Ed. Manole Ltda. São Paulo, Brasil, 188 p, 1990.

SARTORI, L. P.P. Geologia e Geomorfologia de Santa Maria. Ciência \& Ambiente, n. 38, p. 19 - 42, 2009.

STEPHENS, D.B. \& NEUMAN, S.P. Vadose zone permeability test: summary. Journal Hydrology Division, ASCE, v. 108, n. HY5, p. 623-639, 1982

TAVENAS, F.; JEAN, A.P.; LEBLOND, P.; LEROUEIL, S. The permeability of natural soft clays. Part 2: Permeability characteristics. Canadian Geotechnical Journal, v. 20, n. 4, pp. 645-660. 1983.

TAVENAS, F.; TREMBLAY, M.; LAROUCHE, G.; LEROUEIL, S. In situ measurent of soil permeability in soft clays. In: CONFERENCE OU USE OF IN SITU TESTS IN GEOTECHNICAL ENGINEERING, 1986, Blacksburg. Proceeding... Blacksburg: ASCE, 1986, p. 1034-1048.

TAVENAS, F.; DIENE, M.; LEROUEIL, S. Analysis of the in situ constant head permeability test in clays. Geotechnical Testing Journal, v. 27, p. 305-314, 1990.

WILKINSON, W. B. Constant head in situ permeability tests in clay strata. Geotechnique, v. 18, p. 172-194, 1968.

UZIELLI, M. Statistical analysis of geotechnical data. In: INT. CONF. ON SITE CHARACTERIZATION, 3, 2008, Taipei. Proceedings... Taiwan, Taylor \& Frances: Balkema, 2008, p. 173-193 